\title{
UNIVERSITYOF
}

FORWARD

THINKING

WESTMINSTER用

WestminsterResearch

http://www.westminster.ac.uk/westminsterresearch

Designing Democratic Innovations as Deliberative Systems: The Ambitious Case of NHS Citizen

Boswell, J., Dean, R. and Smith, G.

This is a copy of the accepted author manuscript of the following article: Boswell, J., Dean, R. and Smith, G. 2019. Designing Democratic Innovations as Deliberative Systems: The Ambitious Case of NHS Citizen . Political Studies. Advanced online publication. doi:10.1177/0032321719866002. The final definitive version is available from the publisher Sage at:

https://dx.doi.org/10.1177/0032321719866002

(C) The Author(s) 2019

The WestminsterResearch online digital archive at the University of Westminster aims to make the research output of the University available to a wider audience. Copyright and Moral Rights remain with the authors and/or copyright owners.

Whilst further distribution of specific materials from within this archive is forbidden, you may freely distribute the URL of WestminsterResearch: ((http://westminsterresearch.wmin.ac.uk/).

In case of abuse or copyright appearing without permission e-mail repository@westminster.ac.uk 


\section{Designing Democratic Innovations as Deliberative Systems: The Ambitious Case of NHS Citizen}

Recent innovations to promote citizen participation in political and policy-making processes have been inextricably connected with deliberative democratic theory. The focus has tended to be on the design and impact of discrete participatory democratic institutions that attempt to approximate deliberative ideals. Yet deliberative theory has recently undergone a systemic turn that is in large part a reaction to these attempts at institutionalising deliberative norms. Where once the literature abounded with good news stories of novel participatory governance initiatives, there is now a growing sense that the concentration on the deliberative qualities of individual forums comes at the cost of the broader and more fundamental project to make democratic systems as a whole more inclusive and reflective (Mansbridge et al., 2012; Owen \& Smith, 2015). This poses the question of how the shift to deliberative systems theory might inform more systems-oriented design thinking for participatory democratic institutions. However, deliberative systems theory has so far remained an analytical enterprise, less concerned with practical questions of democratic design.

This paper engages directly with the question of what a systems orientation to democratic innovation looks like, asking whether it is able to address the frustrations with previous attempts to institutionalise deliberative ideals. We explore these questions through an investigation of a pioneering attempt at democratic innovation: NHS Citizen (NHSC). Soon after NHS England was established in the 2012 Health and Social Care Act, its appointed board began to think about how it might deliver on its new statutory duty to engage with the public. Ideas about how this duty might be carried out rapidly expanded from traditional approaches to stakeholder consultation towards a much more open, multi-faceted and radical design. The aim of NHSC became to tap into, connect up and channel the wide range of different settings of discussion that already exist, sequentially linking wild talk in social media, into spaces of testimony sharing and evidence-giving, right through to the considered deliberations of the NHS England board. NHSC therefore bears remarkable affinities—both in the motivations underpinning its development and in its final model-with recent shifts in deliberative democratic thinking. It exemplifies a shift in focus away from consideration of a single forum which might embody deliberative democratic norms, instead emphasising a range of differentiated settings through which those norms are distributed. NHSC thus offers a fascinating case through which to explore contemporary efforts towards democratic reform that are in line with systemic ideals. Through detailed study of this case, we illuminate the ways a deliberative systems orientation to democratic innovation might enable some creative mitigations to the problems of institutionalisation that have troubled earlier participatory democratic institutions, such as the overweening power of the commissioning organisation and the disconnection from mass publics, as well as highlighting the new challenges it presents, such as the difficulties of incorporating alternative logics of participation and practically defining the relevant boundary of empowered space. 


\section{SYSTEMS THINKING: THE ANTIDOTE TO INSTITUTIONAL DESIGN?}

Systems thinking has become the new orthodoxy in normative deliberative theory (e.g. Dryzek 2009, 2010; Mansbridge et al. 2012; Neblo 2015; Parkinson 2006). Justification of this systemic view explicitly turns upon critiques (both from within and outside of deliberative democracy) of the proliferation of discrete institutional innovations. John Dryzek, for example, contends that "a systemic turn is the antidote to the institutional turn" (Dryzek, 2010, p.7). Similarly, Mansbridge et al. (2012, p.1-2) and Parkinson (2006, p.147) situate their deliberative systems accounts against the scale and legitimacy problems of individual deliberative forums. Criticisms of the previous orthodoxy of democratic innovations can be grouped into three broad institutionalisation problems: the power of the commissioner, disconnection from everyday politics and a lack of legitimation capacity.

One long-running criticism of the institutionalisation of mini-publics and other deliberative initiatives is that, rather than offering an authentic tool for deeper democratisation, they are adopted predominantly as a legitimation tool by public authorities wanting to rationalise and control public debate (Papadopoulos \& Warin, 2007; Parkinson, 2004). The focus on internal dynamics of deliberation within a forum "leaves intact the conventional institutional structures" (Pateman, 2012, p. 10). Within participatory processes commissioned by public authorities, citizens rarely have control over the conditions under which they participate: whether that be who has the right to participate, the design of the participatory institution, or the terms of the agenda on which their views are elicited (Chambers, 2009; Dean, 2017; Parkinson, 2006). The concern, then, is that deliberative forums give too much power to the commissioning organisation, providing a façade for perennial problems of elite and special interest domination (Johnson, 2015).

A second current of criticism is more pragmatic: concern with the realpolitik limitations that prevent democratic innovations from effectively linking either to civil society or empowered governing practices (see especially Papadopoulos 2012). The one-off nature of much democratic innovation precludes integration into the "regular political cycle in the life of the community" (Pateman, 2012, p. 10). Invented 'forums' can crowd out organic forms of civic life and citizen participation (as observed by: Boswell et al., 2015; Martin et al., 2018; Stewart, 2016). In addition, the disconnection from the everyday business of public authorities hampers the capacity of democratic innovations to deliver insights to policymakers that are responsive to their immensely complex agendas and an ever-shifting political context. The claim here is that while political elites may authentically desire public input, prevailing modes of democratic innovation fail to deliver it in a form that is sufficiently usable (see Hendriks \& Lees-Marshment, 2018), thus they become side-lined in favour of other competing institutional imperatives (e.g. Martin, 2011; Newman et al., 2004; Syrett, 2006).

Third, the deliberative systems approach criticises the legitimation capacity of discrete democratic innovations. Given the small numbers of participants that take part, questions arise as to whether even ideally constituted processes can legitimate binding collective decisions in large polities. The systems turn suggests that we should instead expect deliberative and democratic functions to be distributed through a range of differentiated but interconnected settings (Mansbridge et al., 2012). The systems approach is thus a move away from understanding democratic legitimacy through a narrowly prescribed account of 
institutionalisation towards a more complex account that seeks to integrate the variety of institutional structures and wider democratic practices (Parkinson, 2006).

Despite this attention to problems of institutionalisation for discrete forums, the practical implications of systems thinking for the design of democratic innovations have been neglected. The deliberative systems approach is instead more commonly employed as a normative standard, used to theorise and/or empirically evaluate the democratic health of a polity (Burall, 2015). Where it has focused on democratic innovations, it has been concerned with interpreting their effects in systemic terms (see: Curato \& Böker, 2016; Felicetti et al., 2016; Goodin \& Dryzek, 2006; MacKenzie \& Warren, 2012; Niemeyer, 2014). What is entailed by a systems approach to designing democratic institutions, as opposed to a systems approach to evaluating democratic institutions, remains opaque.

Clarity on this question is important because systems theory can and, as our empirical example will demonstrate, is influencing the design of democratic innovations. The longstanding connection between deliberative theory and democratic innovations means theoretical developments have profound impacts on the community of practice interested in pursuing democratic renewal and reform. Indeed, there is considerable interaction, knowledge exchange and movement of skills and insights across the academy-praxis divide in this field. The systemic turn in deliberative theory, in this sense, does not just matter because it changes the analytic construct that political scientists use to analyse and evaluate real-world practices; it also matters because it has potential to re-shape those practices.

By reconstructing the immanent logic of the variety of specifications of the deliberative system, along with their critiques of democratic innovation, it is possible to identify two core propositions that can guide democratic innovation in a more systems-oriented direction. The first injunction for democratic designers is that ensuring transmission between different democratic spaces is just as important as the dynamics within a space (Dryzek, 2010). When a new institutional arena is created, it should be embedded within existing networks and remedy a functional deficit, rather than displacing organic functional activity. Second, a single intervention should not be expected to realise the full panoply of necessary democratic functions (Mansbridge et al., 2012; Parkinson, 2006). Designs will likely have to distribute functions across different arenas, paying careful attention to which functions are realised where, and that the system as a whole is comprehensive. The aim of our analysis is exploratory: to understand the effects of adopting these ideas as design practice. Our ambition is not to apply or develop a new evaluative framework for assessing systemsinspired democratic innovation. Rather, drawing on a pioneering real-world example, we explore how deliberative systems-inspired designs may (or may not) in practice address the problems of institutionalisation that have bedevilled democratic innovations. At the same time we consider whether new challenges emerge from applying this systemic approach to democratic design.

\section{THE CASE: NHS CITIZEN}

NHSC was a participatory initiative launched by the appointed Executive Board of NHS England. It was a response to NHS England's statutory requirement to engage, and Board members' concerns that their decisions lacked public accountability. It was born into a complex institutional context that was in some ways propitious and in some ways challenging. Internally NHSC had influential backers on the Board. NHS England's Public Voice Team, charged with co-ordinating the process, were committed to embedding an 
ambitious participatory structure within the organisation and developed a good working relationship with the consortium of four small organisations with expertise in democratic engagement and public sector innovation - Involve, DemSoc, Public-I and the Tavistock Institute - commissioned to design and deliver NHSC. Nevertheless, support amongst the Board members and other high-level managers was not unanimous. Moreover, the process quickly developed its own momentum that shifted away from the initial proposal.

Inspired by the success of the Joanna Lumley-fronted campaign for Ghurka rights, the initial proposal by the Director for Patient Information, Tim Kelsey, was to convene a national assembly high-profile figures that could hold the Board to account through publicity campaigns in the national media. Over the next few months, other key actors - including NHS England's Head of Public Voice, Olivia Butterworth, and Victor Adebowale at board level - steered the discussion from a focus on celebrity representatives towards a more grass-roots conception of engagement involving service-users and citizens. Plans for a celebrity assembly thus morphed into plans for a national citizens' assembly in which members of the Board would meet with citizens and service-users to discuss NHS England priorities. Once Involve, DemSoc, Public-I and the Tavistock Institute were commissioned, the plans for a citizens' assembly then further developed into the more ambitious design that closely resonates with ideas that inform deliberative systems.

In addition to the internal dynamics, NHS England was only one of the multiple power centres whose support was necessary to make NHSC a success. NHS England was itself a newly created organisation, thus without a pre-existing public. NHSC was an attempt to create this public within what was already a crowded participatory terrain, with a range of existing civil society groups and patient and public involvement structures (see: Dean 2016, p186-197). This was precisely what enabled a systems-orientation with the aim to channel existing activity. However, it also meant there were a number of better established participatory bodies weary of endless institutional reinvention and wary of the possibility of being usurped by NHSC. This was not helped by a febrile political context: NHS England was created under the Conservative-Liberal Democrat Coalition's 2012 Health and Social Care Act, a broad package of health reforms that sparked significant controversy and protest amongst key stakeholders. As is likely whenever circumstances are complex enough to require a systems-oriented intervention, the institutional dynamics within which NHSC was situated were ambiguous, providing grounds for optimism that it could overcome certain problems of institutionalisation, but also significant challenges.

\section{NHS Citizen as a systems-inspired democratic innovation}

NHSC is one of very few examples to take a systems-inspired approach to democratic innovation. Its design incorporated the core claim of deliberative systems theory that different democratic functions are distributed across different arenas. It consisted of several interacting parts categorised into three broad stages - called Discover, Gather and Assembly (see Figure 1 and Figure 2) - each of which had its own function. These functions had a clear resonance with John Dryzek's definition of the component parts of a deliberative system (most recent specification: Stevenson \& Dryzek, 2014). Accordingly, it is an ideal case for understanding how systems-oriented design plays out in practice.

Dryzek divides democracy into three parts: private space, where political conversations and interaction take place in everyday contexts; public space, contexts that have been created to discuss political concerns; and empowered space, where binding collective decisions are made. His approach is concerned with processes of transmission, whereby private and 
public spaces influence empowered space, as well as the accountability of empowered space to public space. The three-part Discover-Gather-Assembly design of NHSC embodied these concerns. It was intended to be a mechanism for moving from conversations and discourses in everyday and public space to decision making in empowered space, as well as establishing an accountability relationship between them.

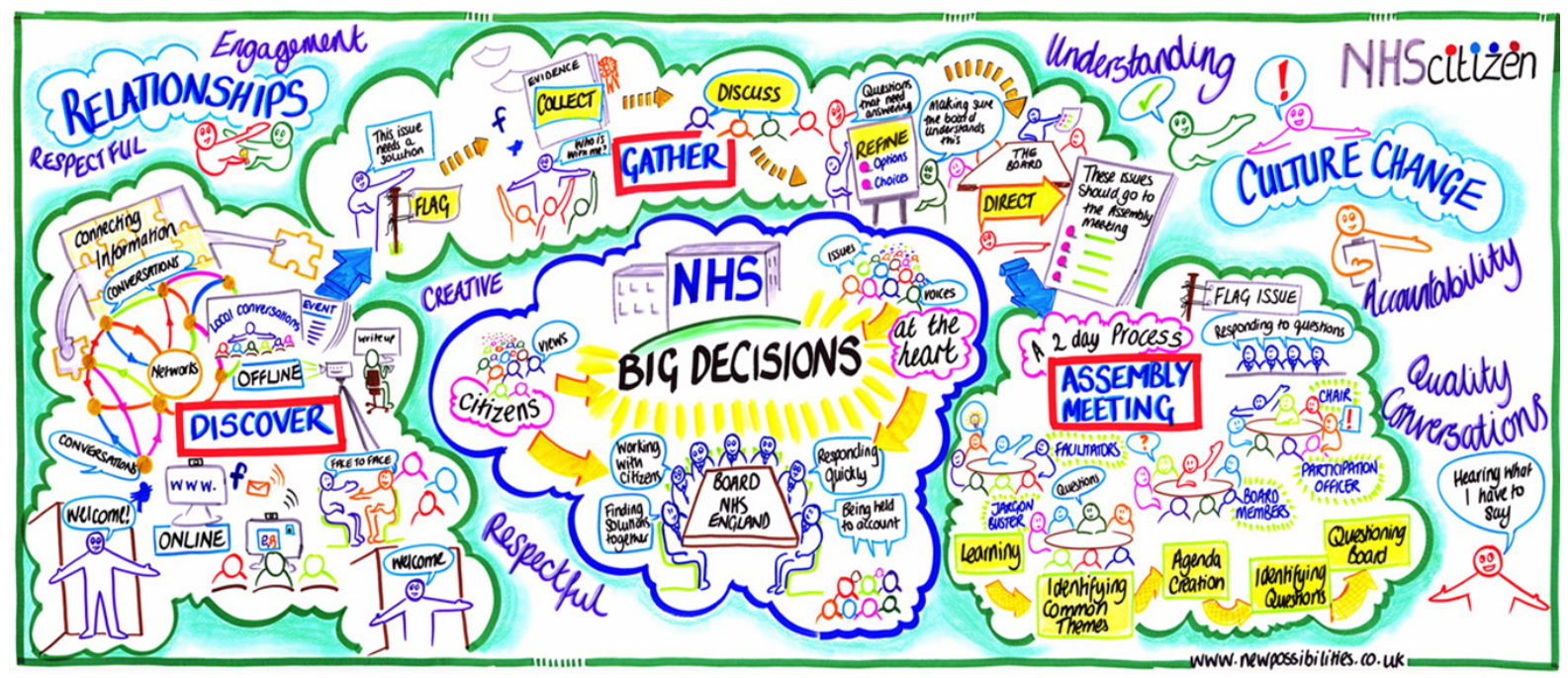

Figure 1: NHS Citizen design

\begin{tabular}{|c|c|c|c|}
\hline Design Component & Purpose & Who participates? & Proposed Scale \\
\hline Assembly & $\begin{array}{l}\text { a) Develop collaborative } \\
\text { solutions to nationwide } \\
\text { issues } \\
\text { b) Hold NHSE Board to } \\
\text { account }\end{array}$ & $\begin{array}{l}\text { Citizens and Board } \\
\text { members } \\
\text { Offline and online }\end{array}$ & $\begin{array}{l}5-10 \text { issues, discussed by } \\
250 \text { citizens and } 20 \text { board } \\
\text { members. Bi-annual }\end{array}$ \\
\hline Citizens' jury & $\begin{array}{l}\text { Further prioritise issues for } \\
\text { the Assembly }\end{array}$ & $\begin{array}{l}10-15 \text { citizens } \\
\text { Offline }\end{array}$ & $\begin{array}{l}20 \text { issues, } \\
\text { bi-annual }\end{array}$ \\
\hline Gather, deliberation space & $\begin{array}{l}\text { Raise / discuss / resolve } \\
\text { issues. } \\
\text { Prioritise issues for } \\
\text { Assembly agenda }\end{array}$ & $\begin{array}{l}\text { Open to everyone. } \\
\text { Online and offline }\end{array}$ & $\begin{array}{l}200 \text { issues being worked } \\
\text { on at any one time. } \\
\text { Ongoing }\end{array}$ \\
\hline $\begin{array}{l}\text { Discover, active listening } \\
\text { and connected } \\
\text { conversations }\end{array}$ & $\begin{array}{l}\text { Collect evidence/issues } \\
\text { from ongoing } \\
\text { conversations }\end{array}$ & $\begin{array}{l}\text { Open to everyone (Active } \\
\text { citizens who have agreed } \\
\text { to participate and have a } \\
\text { participation passport) } \\
\text { Online and offline }\end{array}$ & $\begin{array}{l}100,000+\text { people } \\
\text { Ongoing }\end{array}$ \\
\hline
\end{tabular}

Figure 2: Key components of NHS Citizen

Discover would identify and map conversations about the NHS occurring in existing online and offline networks that cut across everyday and more public spaces. Gather provided a more formal online public space in which participants in NHSC could actively raise and discuss issues. These issues could be those identified in Discover or brought forward by 
citizens, civil society groups or employees of NHS England amongst others. There was a longer-term ambition that the Gather space could itself become a site for the coproduction of solutions between citizens/service-users and NHS professionals and managers - an ambition that it would also have empowered characteristics. Any issues relevant to nationallevel NHS England policy identified through these two stages then went through a prioritisation process - a Citizens' Jury - with those deemed most important forming the agenda for the biannual Assembly attended by the NHS England Board. In addition, the system operated with a 'no wrong door' policy, so issues inappropriate for the national-level Assembly were directed to other relevant NHS organisation. The Assembly was additionally expected to function as the primary site in which the NHS England Board was rendered accountable to the public, explaining actions taken to address issues from previous assemblies. Although only 250 people could attend the Assembly, it was also live-streamed meaning that this process of public justification could have an unlimited audience.

NHSC additionally incorporated another important component from Dryzek's deliberative systems approach. There was extensive meta-deliberation concerning the shape of the system itself. The design phase was conducted in the open, with a number of workshops held around the country to solicit feedback on and test the process. This was accompanied by a culture change programme to prepare NHS organisations (empowered space) for a more participatory mode of decision-making. As such, there was a broad-based attempt to engage all relevant stakeholders in meta-deliberation about the shape NHSC should take.

Our interpretation of NHSC as an attempt to realise a systems innovation is also supported by the ways the designers articulated their practice. During our empirical research, one of the lead protagonists referred to NHSC as "a multi-stage, information-led, participatorydeliberative system". The design team always intended to develop a systems approach to engagement and became familiar with the language and concepts of deliberative systems as the process developed. For example, during the design and implementation of NHSC, the Director of Involve, Simon Burall, held a visiting fellowship at the Centre for the Study of Democracy at the University of Westminster, where he was working on and later published a report reflecting on the ways in which the debate on deliberative systems might affect the work of democratic practitioners (see Burall, 2015). While NHSC could not be described as a self-conscious application of these ideas - Burrall himself acknowledges that he and the other architects of NHSC did not start the process with such a sophisticated theoretical understanding - it is clear that the practical design was informed by and inflected with exactly the sorts of concerns which have underpinned the systemic turn in deliberative democratic theory (see also Bussu, 2019).

\section{Data collection and analysis}

Our analysis of NHSC is based on a rich qualitative dataset. We drew on archived material from the NHSC website, including video content, graphic records and text documents associated with both the meta-deliberation in design workshops and the substantive deliberation off- and online. We observed and participated in two design workshops in 2014 and 2015. We conducted a two-hour focus group with the four key civil society designers of the process, following on from an earlier interaction at a reflective roundtable during the 2014 PSA Conference in Brighton. The final phase of data collection entailed interviews. We identified participants both through these earlier phases and then subsequent 'snowballing' in interviews. To ensure a diversity of perspectives we selected participants with different roles in and relationships to NHSC. This resulted in seven additional key informants, 
including two NHS England employees, an NHS England Board member, two process managers involved in the day-to-day running and delivering NHSC, one civil society activist who participated in the process and one academic critic of the process. Interviews lasted between two hours and 15 minutes, but in practice most were 45 minutes to an hour. We determined we had reached 'saturation' point once we stopped hearing new interpretations in the interviews that participants were willing to grant us. It is important to reflect here that we were not able to access critics of the process from within NHS England, who were predictably less enthusiastic to talk about the initiative.

Our approach to the analysis of this data was interpretive in nature. Interpretive research aims to elicit participants' own understandings of social and political phenomena, and to draw on the narratives they tell to make sense of their experience in order to explain outcomes. Interpretive research has been at the forefront of empirical research into deliberative systems because it is well-suited to unpacking the rich features of deliberative practices in context (see Ercan et al., 2017). As such, it is ideally suited to exploring and teasing out the dynamics of an open-ended, organic process like NHSC. In practice, then, we engaged in a form of abductive reasoning (see Schwartz-Shea \& Yanow, 2011) in manually coding and presenting the data and analysis. Given our intention to use the case to interrogate propositions generated from theory - what Blatter and Blume (2008) call a 'congruence' approach to case study research - we started with analytical categories drawn from the literature across deliberative systems and democratic innovation, refining them in light of our analysis in an iterative process. This approach enables us to use the story of NHSC, as it is interpreted by those who were involved, to explore the potential and challenges of systems-oriented democratic innovations, drawing out the broader lessons from this case for the theory and practice of deliberative systems and democratic innovation.

\section{ANALYSIS: THE PROMISE AND PERILS OF SYSTEMS- ORIENTED DESIGN FOR DEMOCRATIC INNOVATIONS}

\section{A) Challenging the power of the commissioner}

If traditional democratic innovations have often ceded too much power to the commissioning organisation, could a systems approach focussed on transmission from private and public to empowered space do a better job of bottom-up agenda-setting? Initially, it seemed as if NHSC was born into a benign context conducive to such an approach. The designers were excited by the opportunity that NHSC presented. One described it as "catnip to the democratic practitioner":

It was pretty irresistible wasn't it, the idea of it being about being able to take democracy into the heart of a massive piece of bureaucracy which had just had its democratic accountability ripped away through an injudicious act of parliament. If you're interested in democracy and you're interested in public service reform, for me, it was irresistible. (Focus Group)

Key to this enthusiasm was the apparent attitude of NHS England. NHS England's Public Voice team, which oversaw the process, was seen to be an ideal commissioner.

I think also one of the things that attracted me to it was the fact that the client... seemed to be so in the same place on the things that we wanted to 
do, and was very up for doing something radical and very up for doing something different. (Focus Group)

Importantly, the initiative had key champions on the NHS England Board who not only supported the objectives of the participatory process, but also commissioned a 'culture change' programme at least in part to foster a more participatory organisation internally. One of the board-level champions of NHSC explained that "I learned this the hard way from previous attempts to engage people that you needed the leaders". Sensing some anxiety about engaging directly with the public amongst other Board members and professionals within NHS England, the Tavistock Institute, an organisation with expertise in developing a participatory working culture in the public sector, was engaged to work specifically with senior professionals within NHS England and secure their buy-in to the new way of working that NHSC would require.

Despite the early promise, it soon became clear that NHSC, like most democratic innovations, was surrounded by complex organisational politics. One of the board-level champions reflects that his enthusiasm may not have been shared by colleagues, but they were initially unwilling or unable to articulate their concerns:

Everybody agreed with the principle of engaging the public. Because how could you not? It's public service. But... Have you come across the Abilene Paradox? Everybody agrees to do something, but when it's done they all start complaining, asking why did they do it, and that's because they weren't honest about how uncomfortable they were about doing it in the first place. (Interview with a board-level champion)

In addition, NHSC was conceived by the Board at a very particular moment, when there was an absence of everyday business.

It was February 2013 where they met for the first time. They had no responsibilities; they didn't take power until April 2013 and they just lost that link to Parliament and they had a couple of thinkers in there and they were pushed to do it by a couple of board members and that moment will not happen again. (Focus group)

As NHS England's workplan became more concretised, the tensions between its own agenda and an ambitious participation initiative became more apparent:

Then they wrote the Five Year Forward View, and suddenly [the Board] had a business plan to deliver. So, what they didn't want was, the reality is what was much more difficult in that space was to have an open call from Citizen saying this is what we want to talk about. (Focus group)

NHSC thus provides a useful case for examining the prospects of the systems approach to this perennial problem of the power of the commissioner. It was characterised by both the shift from an initially benign context to growing concern from the commissioner, as well as a culture change programme that anticipated and attempted to address this issue.

A quirk of the NHSC design process meant that for the first Citizens' Assembly, Discover and Gather were not fully operational. Issues for the Assembly agenda were selected from Gather, but the agenda prioritisation was not in place, so they were selected top-down by the Public Voice Team. Conscious of proving the utility of the process to Board members, issues were selected that echoed their strategic priorities (interview with a process manager). This approach reflects the kind of 'invited space' that has been critiqued by some scholars for 
drawing citizens into participating, but on terms that favour the concerns of institutional power. From the Board's perspective the Assembly was a success. A process manager in NHS England reported the collective reaction of the Board as "a very positive experience" (Interview with a process manager). It was followed by Board approval for NHSC to continue under the leadership of the original designers in collaboration with the Public Voice team.

Once the full NHSC process began to take root, the Assembly agenda was set bottom-up through the Gather process, and as the implications of this began to emerge, the Board's support waned. The next Assembly was not such a comfortable experience for some Board members:

This is the first full run through of the citizen process, so the issues are not ones that the board identified with. But they were definitely issues that the people in the room identified with ... [We] managed to get groups and organisations involved who wouldn't normally be involved at that level, and we posed very difficult questions to the board. I think by that point they'd got to the stage where they thought, 'we don't know what to do with this, we're potentially building up too much power, the expectation is we're going to be able to do stuff with all this but we can't because it's not in our business plan or board priorities'. (Interview with a process manager)

A Board level champion suggests that as NHSC embedded, a split in the Board became obvious:

More than half the board got more relaxed with each meeting as they understood that the sky wasn't going to fall in and they weren't going to be ripped limb from limb by a baying mob and as they became more comfortable with understanding that the public's concerns were also our concerns and the public's concerns could shed a light on what we were doing which could be quite helpful. But I think there were other members of the board who just thought that this was a waste of time. 'Why are we doing this? What's it for?' (Interview with a board-level champion)

The situation was exacerbated when the main executive champion of NHSC on the Board announced that he was leaving and it quickly became clear that, even with the culture change activity, many Board members were no longer supportive (assuming that they had been in the first place):

... we had been assuming, because [a senior executive] told us, that he was absolutely bringing on all of those colleagues from the Board and that everyone was comfortable with all of this, and as soon as he left, it became incredibly apparent that they weren't very comfortable with it at all. What they wanted was something that was like what we delivered at the first AGM - something relatively comfortable that they could go and be seen to engage and connect and mix with people. (Interview with a process manager)

Central to this concern was the language of accountability. NHSC organizers had advocated that the Assembly's key function was as a site in the NHSC system where the Board could be held to account. But in practice a number of Board members were very uncomfortable at the prospect of being held to account in an unpredictable setting where they may not have access to adequate information, or where subsequent circumstances may force them to change their view (see also Bussu, 2019). A board-level advocate captured the mood colourfully: "[They were thinking] shut this fucker down. I'm not doing that again. I don't want 
to be exposed in public again, this is going to be shut down". On this reading, it was the empowerment of participants through NHSC - their capacity to determine the agenda of what was discussed in the Assembly - that was the death knell for the process.

The lessons for whether a systems-oriented design can rebalance the power between participants and commissioner are somewhat ambivalent. In one sense the story is positive: NHSC pioneered an approach for transmitting concerns from private and public space onto the agenda for discussion in empowered space. It even had some modest successes in attracting attention to issues outside the Board's strategic focus - notably in relation to care for transgender patients and in mental health treatment. Nevertheless, the process proved so uncomfortable for some of the institutional actors that it triggered a power-play to terminate the entire process.

The culture change programme proved ineffectual in addressing this issue. One of the Board champions reflected on the Tavistock Institute's attempts to assuage concerns of other board members and secure their buy-in to the process,

Now, the first clue, was the difficulty that the Tavistock Institute were having in getting time in people's diary. The more senior they are, the more freedom they have over their time. So, if they choose not to do this, then, you know... So that was really difficult and the Tavistock people, really smart people these were highly qualified people - and they were asking "Are they really committed?" And I was "Yeah, yeah, of course they are." But I was thinking "Oh shit, l'm not sure they are!"

Organisational culture change is difficult enough to achieve from the top when there is strong commitment, but this was an attempt at horizontal culture change. It was championed by Board members trying to change the attitudes and behaviours of their peers rather than their subordinates, thus it was extremely easy for the other board members to resist through noncompliance. One of the designers commented on their resultant powerlessness, "we were like ants crawling up the elephant's leg going, if we just get behind the ears then we can steer" (Focus group).

The experience of NHSC sheds light on the central notion of 'transmission' in deliberative systems and its implications for democratic design. The components of the initiative connected neatly in theory and on an artist's sketchbook, but in practice empowered actors lost enthusiasm the more authentic the transmission from public space threatened to become. This suggests an especially crucial role for 'transformation' as ideas and claims move from public space and inevitably confront technical and administrative obstacles in empowered space (see Neblo, 2005). The mere presence of institutional links is insufficient to ensure authentic transmission, as empowered elites can mischaracterise ideas and claims emerging from public space, or dismiss them as unfeasible (see Boswell et al., 2016). A systems approach to design must be attuned to how and how closely the claims and actions of empowered elites map onto the public's preferences. NHSC's culture change programme represented a key nod in this direction. But this aspect of the design was under-resourced reflective of a more general theme we turn our attention to next.

\section{B) Sustainable funding}

While realising sustainable funding is a common problem for institutionalising democratic innovations, developing a systems-oriented design significantly complicates the issue. 
Discrete democratic innovations have been criticised for a lack of adequate resourcing to support anything beyond a short-term, project orientation (see especially Lee, 2014). But commissioning a Citizens' Assembly is much simpler than commissioning a systems intervention. The former is a well-established participatory 'technology' that can be easily costed, and it is clear to public organisations what they are buying. A systems intervention that attempts to take account of institutional context, harnessing existing activity and making connections between different organisations, is always likely to be a more bespoke affair. In addition, if the design is to incorporate genuine meta-deliberation regarding the shape it should take, then it is not possible to know ex-ante what is being commissioned. NHSC was exactly this type of process and it produced significant tensions with public service procurement practices.

The only way to fund NHSC whilst respecting the NHS' procurement rules was through a series of short-term grants. The designers of NHSC reflected on how it was impossible to design systemically - in particular Discover and Gather - without proper resources.

I've wondered whether one of the hidden consequences of the bad procurement method was we never had visibility that something was going to carry on long enough to enable us to put the structures in place, to enable it to work right... We only knew we had this much till then, then this much till then, and it was always very ad hoc and never certain. (Focus group)

This funding arrangement also played into the outsized power of the commissioning organisation. While no explicit decision was made at Board level to "kill" NHSC, as powerful Board members increasingly felt uncomfortable with the initiative, funding to the designers began to dry up. What was relatively small money for NHS England was a significant proportion of income for these small organisations. Without guaranteed funding they increasingly spent time that could have been devoted to improving NHSC worrying about their financial sustainability. As resources stopped flowing, NHSC slowly wound down without any public justification of the decision having to be made. As one of the designers noted dryly: "It was like a Beckett play, some bizarre non-ending ending" (Focus group). While board level champions attempted to free up funds, they were faced with a resistant bureaucratic system:

What happened was it got harder and harder to fund the organisations... it became harder and harder to squeeze the money out of NHS England. NHS England has a byzantine process of agreeing spending. It is supposed to stop you from spending anything and the small organisations didn't have any resources so they had to be paid on time and it was increasingly difficult to get the system to pay them. Decisions were just held and one by one, they [the designers] were saying 'we can't carry on like this, we can't get anyone to pay us or agree that they will pay us or put us on the budget'. (Interview with a board-level champion)

NHS England enacted 'death by procurement' as it became uncomfortable with the direction of the process. The sustainability of financing for a systems approach is an important issue. It is questionable whether systems-oriented democratic innovation is practicable given current public procurement rules (in England). Designing a participatory-deliberative system that works as an ongoing process requires an approach to sustainably finance that system, one which does not give the commissioning organisation power to terminate the process as soon as it becomes challenging. 


\section{C) The pragmatic limits to meta-deliberation}

NHSC took a radically transparent and self-reflexive approach to development, which the lead organisations termed 'designing in the open' - or 'meta-deliberation' in deliberative systems terms. Rather than inviting participants into a ready-made structure, NHSC invited participants to help shape the design of the democratic innovation. Open workshops were held around England to discuss the design, and at the end of these sessions participants were invited to redraft the system along with the four lead organisations. All key meetings were webcast and archived, with design documents freely available online ${ }^{1}$. NHSC also had a significant social media presence, promoting these materials and extending access to the design process, for instance, by enabling remote participation in the design meetings. This extensive meta-deliberation process was a very public performance of openness and adaptability, as opposed to a long tradition of carefully controlled and stage-managed consultation.

Some participants welcomed this approach, seeing in it an authentic commitment to do participation differently:

I was impressed by the desire on the part of the folk from NHS to make this work and how passionate they were about patient participation... I suppose it was quite, it struck me, as refreshing, quite democratic, quite brave really, to open the floor to everybody. (Interview with a participant)

But other participants were sceptical about how much latitude they really had to influence the overall design:

Despite the fact that it brought a number of people in who voiced some more views, it was predetermined. They knew what they wanted. They wanted a National Assembly and they weren't listening to people even then. So, I attended three meetings and walked out on the third. (Interview with a participant)

The organisers themselves noted this challenge of co-designing NHSC, recognising they ought to have been clearer about what was open to change and what had been negotiated between themselves and NHS England.

I'm not sure we made the shift early enough in those workshops about how the decision was going to be made, who was taking it. I think we failed there to place our own decision making structure with clarity about who was going to be involved and how it was going to happen, and we weren't able to be open about it. And so, for those people who took part, most deeply from the citizen side, those designs [based on decisions made by organisers and NHS England] suddenly seemed a bit opaque and odd. (Focus group)

The meta-deliberation process to design the participation system therefore faced similar charges to those often levelled at participatory initiatives: that the organisers have too much power relative to the participants, and that consultation was mis-sold as coproduction.

Tensions within the design process particularly became apparent when the designers' proposed using random selection at two points. The first concerned how to transmit and prioritise issues from Gather for the Assembly agenda. The designers proposed inserting a citizens' jury between Gather and Assembly. There needed to be a fair and legitimate

\footnotetext{
${ }^{1}$ Unfortunately these materials have since been taken offline, once NHSC was wound-down.
} 
method of deciding which of the many issues raised in Gather should be taken to the biannual Assemblies. Their solution - reasonable from a democratic innovations perspective - was that proponents of issues should be able to present them to a randomly selected group of citizens, who would then make impartial judgements about which issues would go forward. But this decision provoked a heated debate within Gather as active participants in NHSC saw their power being usurped by a randomly selected body. Similarly, when the designers suggested the Assembly should be randomly selected, there was resistance. One critic posted the following attack on the NHSC website:

A ballot was held to decide which items should be sent to a secret meeting, where a group of 15 anonymous people would vote on which items were to be sent to be chatted about by 250 people in London. 250 people who'd never contributed to Citizen before. ('Cassandra', online commenter)

It is ironic that the meta-deliberation, aimed at improving the legitimacy of participation, was charged with similar forms of illegitimacy often directed against more traditional participatory procedures. The critique draws attention to the importance of considering the corporeality of meta-deliberation when building it into democratic innovation. Meta-deliberation is itself a process that must be enacted, directed and managed. This process needs just as much attention as the process it is intended to produce. Moreover, it is likely to be contested. There thus remains a question-mark over whether meta-deliberation resolves problems of institutionalisation or just displaces them to a new arena.

\section{D) The pragmatic limits of distributing democratic functions}

An intervention in which different arenas perform different functions promises the possibility that the overall design can integrate a range of different participatory logics to generate a more comprehensive form of legitimacy (Dean, 2017). NHSC for example aimed to harness the connections and expertise of civil society groups to surface the most important health policy issues, but filter these through groups of randomly selected citizens in order to get a more inclusive picture of public values, that was not dominated by the most powerful health lobby. In reality this necessitated that participants would be willing to be included in some parts of the process and not others, and that the operational logics of different parts of the process could be firewalled from each other. Both proved difficult to realise in practice.

The designers' perspective was that NHSC as a system should be open to everyone - from groups already actively working with NHS England, to marginalised groups that found it hard to have their voice heard, and citizens who may have had little direct experience of NHS services. Nevertheless, some parts of the system were not open: attendees for the citizens' jury and Assembly were to be randomly selected. It became apparent that some of those who participated in one part of NHSC were not happy about being excluded from other parts - as per the above quote from Cassandra, and the aforementioned reaction from some participants against the move from self-selection to random selection. The meta-deliberation process and the resultant battle over who should attend the Assembly embodied a clash over who and what NHSC was for.

As its name reinforces, NHS Citizen had a broader scope than patient involvement.

The NHS belongs to everybody, but while there are many opportunities to be involved as a patient, there are too few opportunities to be involved as a citizen and owner of the NHS - raising issues that the NHS needs to talk 
about, and shaping its strategy and actions. (Tavistock Institute et al., 2014, p. 3)

A large number of the stakeholders who became involved in the self-selected, metadeliberation process were, however, from patient participation organisations, more familiar with a different logic of participation. For patient groups, their members - or more explicitly, their representatives - were the authentic participants because of their lived experience:

There were individuals who sat on senates or national user groups who were saying "You can't ask the public. They don't know anything. You need to have people who've been through cancer and represent other people because they really know how it works", and they were fighting us all the way. (Focus group)

This generated a tension between the idea of citizen participation and group representation:

I think the people who were participating were often patient activists so they had an understanding of accountability that was very much based on representativeness, right? So, they wanted to have elected representatives at the Assembly, and we were doing something different. So a lot of the choices around the design of the Assembly and who to invite were also trying to be a compromise between what they asked, their concerns, and what we felt based on the literature and based on the initiatives that we thought would work best. (Interview with a process manager)

These were not simply abstract conceptual debates within the design process, but had real consequences for how NHSC was eventually realised. In the end, the designers adopted a compromise that integrated random selection of ordinary citizens with inclusion of patient representatives from relevant stakeholder groups. While experimenting with random selection and interest group representation has been tried in other settings such as G1000 Netherlands (where organisers attempt to recreate 'the system in one room'), it is a difficult combination of selection mechanisms to justify. Should we understand the Assembly as a space where service users can coproduce commissioning strategies with Board members or where citizens hold NHS England to account for pursuing broadly held public values about NHS services?

This tension regarding what NHSC was for permeated the entire process. Designing a complex system means you can promise: to build an organic social movement, and to manage a carefully channelled form of public engagement; to enable mutual engagement between policy elites and participants in the process, and to hold the NHS England Board to account; to hear from participants as citizens and as patients. This is not to suggest these promises were disingenuous. All these claims were true of the process itself; they were true of what the architects behind NHSC hoped to achieve. Yet in practice it was difficult to corral these different ideas into different parts of the system, when that system is being designed as a process. Instead, their competing logics bled into one another, causing significant tensions that shifted the design in particular directions. As one lead designer reflected:

[If] you're designing for something that is for a general audience, you need to have a broader set of users than the people who are most interested in spending a day in a workshop with you, talking about this ... They weren't the worst people. They were wonderful people! But at the same time they (we) designed something that was not useful for the normal human being, 
without an amount of knowledge and time commitment that realistically people don't have for the NHS. (Focus group)

By its end NHSC was unable to clearly delineate different arenas for different functions. All aspects incorporated, at least partly, a patient participation logic, and when the designers attempted to diverge from this they met resistance.

This has important implications for the core claim of the deliberative systems approach: that distributing functions across a system will result in greater legitimacy. The systems account may be a more realistic and nuanced vision of normative legitimacy in democratic governance, but it is complex and counterintuitive. One of NHS England's process designers commented on how it is hard to communicate the complexity of a systems logic and design:

I think it became [the lead contractors'] vision and I think they were intellectually honest in that everything was open for comments and input from the public and they put a lot of effort in organised workshops where there was a real effort to incorporate the input we got from the patient activists and the staff and whoever decided to participate. But at the same time, I think the people participating even felt like they couldn't catch up... I think sometimes they struggled to communicate their vision properly. (Interview with a process manager)

For normative legitimacy to translate into perceived legitimacy it would be necessary for participants and observers to adopt a systems perspective. But does anyone apart from democratic theorists and institutional designers take a systems perspective? The evidence from NHSC is people took a citizens-eye view (Stewart, 2016) rather than a systems perspective. Participants struggled to understand even this relatively small system, how its components fit together, and why different components might operate on different logics. Instead they wanted a more uniform approach. Thus, distributing functions across a complex process actually created legitimacy problems.

\section{E) The boundary problem}

NHSC aimed to avoid the charge directed against so many democratic innovations that they are insulated from and displace more organic participatory activity. From the outset there was an awareness that it operated in an institutional space crowded with a variety of participation mechanisms. One of the NHSC design documents was careful to articulate how the process did not intend to displace existing activity, but support it:

NHS Citizen will connect and support existing patient and public involvement work, it will not duplicate or further fragment it. (Tavistock Institute et al., 2014, p. 3)

Rather than substituting for existing activity, in many ways the success of NHSC was predicated on other autonomous activity. For example, Discover, which intended to use webscraping tools to surface issues from ongoing online conversations about the NHS, mirroring Mansbridge's (1999) concern with drawing everyday talk into the deliberative system, obviously depended upon the existence of such conversations.

Our interviewees agreed unanimously that NHSC was impressive in its ability to connect with a diverse range of civil society groups. The process leveraged the existing connections of the Public Voice Team, but also went beyond them. This included well-established and 
well-organised patient networks around cancer and mental health, as well as a range of groups that are often neglected in participatory governance initiatives, such as transgender people, gypsy and traveller groups and young offenders. One regular participant in NHSC commented, "I'd never been in a forum where we'd reached out that well" (interview with a participant).

This connective activity, however, generated questions concerning where the boundary of the system lay. Much of what citizens and civil society groups wanted to discuss and influence was outside the remit of NHS England. The designers wanted to avoid the problem of citizens engaging with NHSC then being discouraged and disillusioned when their issue was deemed outside the competence of NHS England and thus not relevant. Essentially, it was decided that NHS England's remit was too narrow a boundary for the system.

Gather was key to extending this boundary, since it potentially enabled the inclusion of issues beyond NHS England's competencies. It was intended to provide an architecture for self-organisation around specific issues: a focal point for democratic engagement by citizens, service-users and NHS organisations, rather than a discrete engagement initiative. It was planned that many issues could be resolved within this space of engagement and coproduction. First, the team facilitating Gather could redirect issues to the appropriate institution at the end of the agenda-setting process. Second, NHS professionals could participate in the Gather space themselves to coproduce solutions with other participants. Both required a connection to a host of other NHS institutions.

Forming these connections was a substantial challenge, compounded by Gather suffering sorely from the aforementioned resourcing problems. Unlike for the NHS England Board, whose needs and desires were paid significant attention in the design process, there was little strategy for ensuring other NHS institutions would use the process. Redirecting issues proved to be difficult: "of course one of the complexities was why would Public Health England [for example] necessarily be on board with that. How do we get their buy in to this process which wasn't their process?" (Interview with a process manager). Whereas NHS England were to be cajoled into seeing the value of NHSC through a targeted programme of culture change, other NHS institutions were meant to simply see the value of joining these discussions for themselves. Although pseudonymous registration makes it impossible to verify, there is no suggestion that front-line NHS employees ever participated in Gather, vitally undermining its ambition to be a space for coproduction. In an overstretched health system, where most staff are already overburdened, this understandably did not occur. The design thus significantly extended the boundaries of empowered space until its scale became almost indefinable. As such, realising a systemic democratic innovation fully connected to empowered space became a Herculean task.

\section{LESSONS FOR SYSTEMS INNOVATION}

Did the systems-oriented approach provide an antidote to the problems of institutionalisation that have troubled discreet democratic innovations? The architects of NHSC were adamant that the model they developed was a success - that in a less hostile context it could have worked more effectively:

Would I use the model [again]? Would I use the multi-stage information-led, participatory system, deliberative system model? Yes. (Focus Group) 
This will no doubt be tested in further experimentation and innovation in different contexts and different scales in years to come. Still, for now, NHSC throws into sharp relief the dilemmas of designing a systems intervention that lives up to the normative standards of the deliberative systems literature.

The systems-oriented design was not able to resolve common problems of democratic innovation. NHSC developed some innovative approaches to addressing the critique that democratic innovations give too much power to the commissioner. It created a multi-stage process for bottom-up agenda-setting, along with pioneering meta-deliberation that enabled input into the design of the innovation. Whilst this prevented the commissioner controlling the agenda and conditions of participation, it had the effect of alienating the NHS England Board. The NHSC system essentially institutionalised the perennial tension between civil society action and demands and governmental administrative activity. Though it exceeded the capacity of traditional democratic innovations to connect to civil society, it still struggled to deliver usable policy insight. Then when the crunch point came, NHS England held the purse strings and could simply shut NHSC down.

This calls into question whether the relationship between public and empowered space is best conceived in terms of transmission (Habermas, 1996; Stevenson \& Dryzek, 2014). To think of it as a transmission problem suggests democratic designers only need open channels of communication that can transmit from the former to the latter. NHSC opened an effective channel of communication for taking the agenda of public space into empowered space, but this transmission was rejected, because it was not perceived as useful to the established priorities of NHS England. Systems interventions thus need to go beyond transmission, and take 'transformation' just as seriously. In other words, we need to pay much more attention to the ways in which ideas from public space are considered within empowered space. These different discursive settings will have different norms and rely on different forms of rationality. In our case, we observe a gap between the everyday experience of the service user and the administrative logic of the NHS England board. The risk is that ideas and claims emanating from public space become 'lost in translation', either because they make little sense to empowered actors, or because empowered actors distort or dull their meaning. As such, we need to consider means by which the claims of public space are taken seriously following transmission. This may be achieved by, for example, reducing empowered space's power to reject outright, or creating the conditions under which actors from public and empowered space co-create mutually acceptable agendas.

Systems-oriented democratic innovation also brings into focus a new range of conceptual and pragmatic issues. First, it raised the conceptual problem of how legitimacy is to be understood in a system. Where functions are distributed, different forms of legitimacy will be in play that will have an effect on the overall legitimacy of the system. Where systems theorists want us to pay particular attention to the deliberative legitimacy of the whole system (Mansbridge et al., 2012; Stevenson \& Dryzek, 2014), those participating in the system are more likely to be interested in the workings of specific parts rather than the qualities of the whole.

A second, equally complicated issue, is the boundary problem. This has been a negligible issue for traditional mini-publics, which have tended to be commissioned by a single empowered actor to deal with a defined issue, but it was an important consideration for NHSC. There is an implicit assumption within deliberative systems theory that the boundaries of deliberative (or otherwise democratic) systems are both definable and scalable to multiple levels of government and across sectors (see especially Mansbridge et al., 2012). Yet for NHSC it proved difficult to define the boundary of the system. It would 
have made little sense to design boundaries in advance, since the boundary was determined by the limits of the issues raised through the process. Nevertheless, the attempt at ad hoc extension, by directing issues to other relevant authorities, drew such a broad boundary that it was impossible for the initiative to penetrate this vast space. Some other institutions were brought into the initiative, but these were just a handful among potentially thousands of relevant partners. There were only very weak incentives for other NHS professionals and organisations to engage in an initiative they had not commissioned. This poses an important question about the commissioning of systemic democratic innovations, since it is difficult to see how any process commissioned by a single organisation on this kind of scale would have been able to map, then reach out to, a sufficient proportion of the health and social care stakeholders operating in England. As the number of potentially relevant actors proliferates, systems-oriented democratic innovation bumps up against the messiness that prevails across real-world governing silos.

\section{CONCLUSION}

The designers of NHSC were inspired, at least in part, by a desire to create a 'participatorydeliberative system'. This opened the space for a critical examination of the prospects of a systems-orientation to democratic innovation. Our approach was not to apply a deliberative systems framework to evaluate NHSC but to explore the ways systems-oriented intervention might mitigate the common problems of institutionalisation experienced by previous rounds of democratic innovations. We found that NHSC still struggled with a number of these problems, especially the outsized power of the commissioner and the inability to deliver what is perceived to be usable policy input by actors in empowered space. It is, however, too early to conclude that systemic democratic innovations are irredeemable. There are in practice degrees of success and failure, defined by the parameters of the particular political and institutional context. As a first attempt, NHSC pioneered some cutting-edge innovations. It trialled novel ways of connecting civil society actors into the agenda-setting of a deliberative mini-public, embarking on a culture change programme within the commissioning body, and developing a participatory initiative through meta-deliberation about the design. It also achieved modest, but direct, policy impact in a couple of specific areas. These suggest promising signs that can be built upon for further practical experimentation.

Whether systems-oriented democratic innovation is viable remains a live question though. From our analysis, we believe the success of future attempts will turn on three questions. First, can a sustainable connection be established between actors in public and empowered space that does not necessitate the former to forego their own agenda or make the latter feel compelled to 'shut the fucker down' when inevitably challenged or discomforted? Second, is it actually possible to get participants to sign up to the complex idea of legitimacy entailed by distributing different functions between different arenas and operating different parts of the process on different logics? Third, how do we practically draw the boundary of the system and ensure all the relevant organisations within that boundary participate? The answers to these questions are unlikely to be simple. If they prove unanswerable, it would pose a further question for deliberative systems theorists: is systems theory limited to evaluating existing arrangements, or does it provide any guidance for how to intervene to improve democracy? 


\section{REFERENCES}

Blatter, J. \& Blume, T. (2008). In Search of Co-variance, Causal Mechanisms or Congruence? Swiss Political Science Review 14(2): 315-356.

Boswell, J., Settle, C. \& Dugdale, A. (2015). Who Speaks, and in What Voice? Public Management Review 17(9): 1358-1374.

Boswell, J., Hendriks, C.M. \& Ercan, S.A. (2016). Message received? Examining transmission in deliberative systems. Critical Policy Studies 10(3): 263-283.

Burall, S. (2015). Room for a View. London: Involve. Retrieved from https://www.involve.org.uk/wp-content/uploads/2015/10/Room-for-a-View.pdf

Bussu, S. (2019). Collaborative Governance. In O. Escobar \& S. Elstub (eds.), Handbook of Democratic Innovation and Governance. Cheltenham: Edward Elgar.

Chambers, S. (2009). Rhetoric and the Public Sphere: Has Deliberative Democracy Abandoned Mass Democracy? Political Theory 37(3): 323-350.

Curato, N. \& Böker, M. (2016). Linking mini-publics to the deliberative system. Policy Sciences 49(2): 173-190.

Dean, R.J. (2016). Democratising Bureaucracy. PhD Thesis: London School of Economics. Retrieved from http://etheses.Ise.ac.uk/3486/1/Dean_Democratising_Bureaucracy.pdf

Dean, R.J. (2017). Beyond radicalism and resignation: the competing logics for public participation in policy decisions. Policy \& Politics 45(2): 213-230.

Dryzek, J.S. (2009). Democratization as Deliberative Capacity Building. Comparative Political Studies 42(11): 1379-1402.

Dryzek, J.S. (2010). Foundations and frontiers of deliberative governance. Oxford: Oxford University Press.

Ercan, S.A., Hendriks, C.M. \& Boswell, J. (2017). Studying public deliberation after the systemic turn: the crucial role for interpretive research. Policy \& Politics 45(2): 195-212.

Felicetti, A., Niemeyer, S. \& Curato, N. (2016). Improving deliberative participation: connecting mini-publics to deliberative systems. European Political Science Review 8(3): 427-448.

Goodin, R.E. \& Dryzek, J.S. (2006). Deliberative Impacts: The Macro-Political Uptake of Mini-Publics. Politics \& Society 34(2): 219-244.

Habermas, J. (1996). Between facts and norms. (W. Rehg, trans.). Cambridge: Polity Press. Hendriks, C.M. \& Lees-Marshment, J. (2018). Political Leaders and Public Engagement. Political Studies OnlineFirst.

Johnson, G.F. (2015). Democratic Illusion. University of Toronto Press.

Lee, C.W. (2014). Do-it-yourself democracy. Oxford University Press.

MacKenzie, M.K. \& Warren, M.E. (2012). Two Trust-Based Uses of Mini-Publics in Democratic Systems. In J. Mansbridge \& J. Parkinson (eds.), Deliberative Systems. Cambridge: Cambridge University Press. 
Mansbridge, J. (1999). Everyday Talk in the Deliberative System. In S. Macedo (ed.), Deliberative Politics. Oxford University Press.

Mansbridge, J., Bohman, J., Chambers, S., Christiano, T., Fung, A., Parkinson, J., Thompson, D.F., Warren, M.E. (2012). A systemic approach to deliberative democracy. In Deliberative Systems. Cambridge University Press.

Martin, G.P. (2011). The Third Sector, User Involvement and Public Service Reform. Public Administration 89(3): 909-932.

Martin, G.P, Carter, P. \& Dent, M. (2018) Major Health Service Transformation and the Public Voice. Journal of Health Services Research \& Policy 23(1): 28-35.

Neblo, M.A. (2005). Thinking through Democracy. Acta Politica 40(2): 169-181.

Neblo, M.A. (2015). Deliberative Democracy between Theory and Practice. Cambridge: Cambridge University Press.

Newman, J., Barnes, M., Sullivan, H. \& Knops, A. (2004). Public Participation and Collaborative Governance. Journal of Social Policy 33(02): 203-223.

Niemeyer, S. (2014). Scaling Up Deliberation to Mass Publics. In M. Setälä (ed.), Deliberative Mini-Publics. ECPR Press.

Owen, D. \& Smith, G. (2015). Deliberation, Democracy, and the Systemic Turn. Journal of Political Philosophy 23(2): 213-234.

Papadopoulos, Y. (2012). On the embeddedness of deliberative systems: why elitist innovations matter more. In Deliberative Systems. Cambridge University Press.

Papadopoulos, Y. \& Warin, P. (2007). Are innovative, participatory and deliberative procedures in policy making democratic and effective? European Journal of Political Research 46(4): 445-472.

Parkinson, J. (2004). Why Deliberate? The Encounter between Deliberation and New Public Managers. Public Administration 82(2): 377-395.

Parkinson, J. (2006). Deliberating in the real world. Oxford: Oxford University Press.

Pateman, C. (2012). Participatory Democracy Revisited. Perspectives on Politics 10(01): 719.

Schwartz-Shea, P. \& Yanow, D. (2011). Interpretive Research Design. New York: Routledge.

Stevenson, H. \& Dryzek, J.S. (2014). Democratizing Global Climate Governance.

Cambridge: Cambridge University Press.

Stewart, E. (2016). Publics and Their Health Systems. London: Palgrave Macmillan.

Syrett, K. (2006). Deconstructing Deliberation in the Appraisal of Medical Technologies. The Modern Law Review 69(6): 869-894.

Tavistock Institute, Involve, DemSoc \& Public-i. (2014). NHS Citizen Vision. Version 7. Retrieved from http://webarchive.nationalarchives.gov.uk/20141010132304/http://www.nhscitizen.org.uk/ho w-it-works/development-and-vision/ 